\title{
LOS ESPACIOS DE LA SOKA GAKKAI: HACIA LA CONSTRUCCIÓN DE UN BUDISMO HUMANISTA
}

\author{
- DENISE WELSCH ${ }^{1}$ \\ Licenciada en Ciencias Antropológicas de la Universidad de Buenos Aires. Becaria doctoral UBA del Instituto de \\ Ciencias Antropológicas de la Universidad de Buenos Aires. E-mail de contacto: welschde@gmail.com.
}

Recebido em: $14 / 06 / 2020$

Aprovado em: 2008/2020

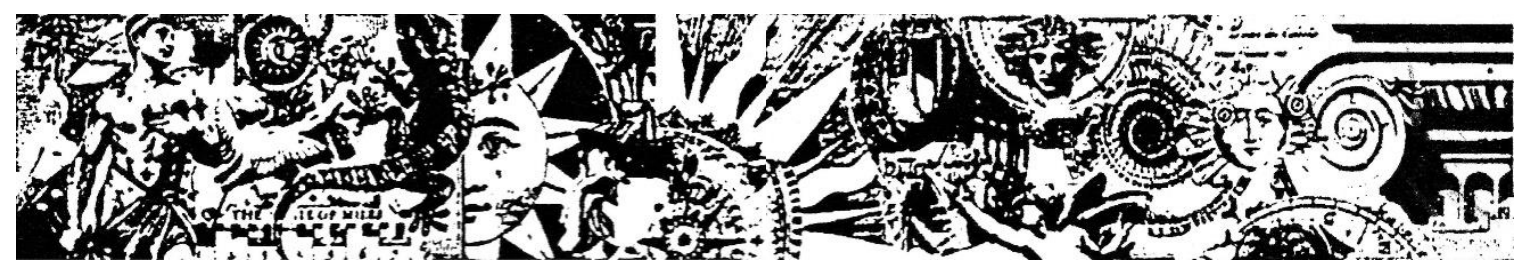

Resumen: En este trabajo analizaré los madas en que la Soka Gakkai Internacional de Argentina opera sobre la dimensión espacial, tomanda en cuenta las estrategias utilizadas en distintas contextas. Partiré de la descentralización espacial que la caracteriza camo determinante de sus distintas formas de intervenir sobre los espacios. Me referiré brevemente a las prácticas de sacralización estables que se observan en los espacios destinadas a su práctica budista, en oposición a los procesos de acomodación cambiantes en los espacios dande se realizan los eventos en los que la organización interactúa con un pública más ampliq, que además de sus miembros incluye agentes culturales y funcionarios estatales. Estos procesos de acomadación están orientados a producir la imagen de una QNG humanista sacialmente comprometida como estrategia para posicionarse sacialmente. Desde una perspectiva que da cuenta de la multiplicidad de actores interactuando en un mismo tiempo-espacio, examinaré cómo la institución, en tanto organización humanista, establece vínculas con el Estado y lo que sucede al mismo tiempo can sus miembras, entre quienes, como consecuencia, la identidad colectiva budista parece fartalecerse.

Palabras-Clave: Saka Gakkai, espacio, budismo, humanismo, sacralización, acomodación. 


\section{SDKA GAKKAI’ S SPACES: TOWARDS THE CUNSTRULTIION QF A HUMANIST BUDDHISM}

ABSTRACT: THE AIM DF THIS PAPER IS TO ANALYSE HOW SDKA GAKKAI INTERNACIONAL DE ARGENTINA ACTS UPDN THE SPATIAL DIMENSION CDNSIDERING THE STRATEGIES USED IN DIFFERENT CONTEXTS. I WILL REFER TQ ITS CHARACTERISTIC SPATIAL DECENTRALIZATION AS DETERMINANT OF THE VARIIIUS WAYS IN WHICH IT INTERVENES UPON SPACES. I WILL BRIEFLY ACCDUNT FDR THE STABLE SACRALIZATIINN PRACTICES OBSERVED IN SPACES INTENDED FOR ITS BUDDHIST PRACTICES, DPPDSING TO THE CHANGING ACCDMMUDATION PROCESSES USED IN EVENTS WHERE THE ORGANIZATION INTERACTS WITH A BRDADER PUBLIL, THAT INCLUDES NDT ONLY MEMBERS BUT ALSO CULTURAL AND GQVERNMENT AGENTS. I WILL SUGGEST THAT THESE ACCOMMODATION PROCESSES TAKE PLACE IN ORDER TO BUILD THE IMAGE OF A HUMANIST NGO SOCIALLY COMMITTED AS A STRATEGY TO OBTAIN A BETTER SOCIAL POSITION. FRDM A PERSPECTIVE THAT ACCOUNTS FOR THE MULTIPLICITY OF INTERACTING SOCIAL ACTORS UPON THE SAME SPACE-TIME, I WILL EXAMINE THE RELATIONS BETWEEN SDKA GAKKAI AS A HUMANIST QRGGANIZATION AND THE STATE, AND WHAT HAPPENS AT THE SAME TIME AMUNG ITS MEMBERS, WHERE, AS A RESULT, CDLLECTIVE IDENTITY SEEMS TO BE REINFORCED.

KEYWDRDS: SDKA GAKKAI, SPACE, BUDDHISM, HUMANISM, SACRALIZATION, ACCDMMIDATION

\section{AS ESPACIALIDADES DA SDKA GAKKAI: PARA A CONSTRULC̈̃̃ DE UM BUDISMU HUMANISTA}

RESUMD: NESTE TRABALHQ ANALISAREI AS FURMAS PELAS QUAIS A SDKA GAKKAI INTERNACIONAL DE ARGENTINA DPERA NA DIMENSÃ̃ ESPACIAL, LEVANDO EM CONSIDERAÇÃ AS ESTRATÉGIAS UTILIZADAS NEM DIFERENTES CDNTEXTDS. PARTIREI DA

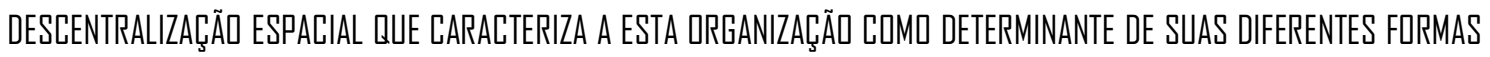
DE INTERVIR NDS ESPAÇDS. VQU ME REFERIR BREVEMENTE ÀS PrÁtICAS DE SACRALIZAÇ̃̃̃ ESTÁVEIS QUE SÃ̃ DBSERVADAS

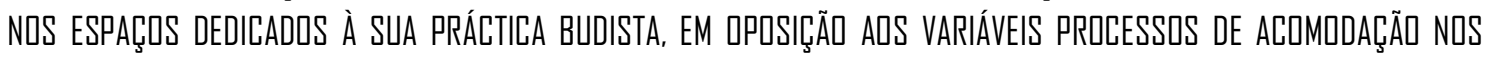

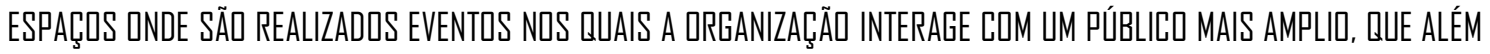
DE SEUS MEMBRDS INCLU AGENTES CULTURAIS E FUNCIONÁRIOS DO ESTADO. VQU PROPOR QUE ESTES PROCESSDS DE ACDMODACÃ̃, VISEM PRODUZIR A IMAGEM DE UMA ING HUMANISTA SOCIALMENTE COMPRDMETIDA, CDMU ESTRATÉGIA PARA SE PDSICIONAR SOCIALMENTE. DE UMA PERSPECTIVA QUE EXPLICA UMA MULTIPICIDADE DE ATORES INTERAGINDD ND MESMD

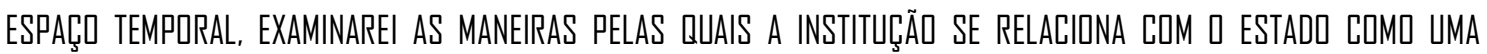

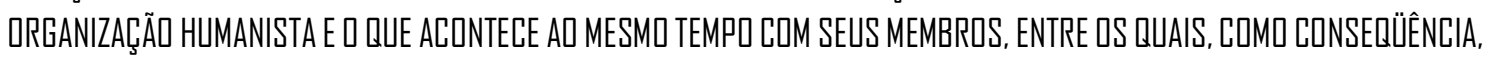
A IDENTIDADE COLETIVA BUDISTA PARECE SER FORTALECIDA.

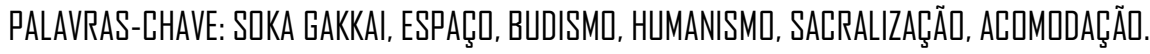

\section{Introducción}

En las páginas que siguen mi objetivo será analizar una cuestión que ya ha sido trabajada ${ }^{1}$, el doble rol religioso y de organización no gubernamental de la Soka Gakkai, organización socio-religiosa transnacional de raigambre budista, pero abordándola desde una nueva perspectiva. Este trabajo estará atravesado por el análisis de la

\footnotetext{
${ }^{1}$ Para el caso brasilero ver BORNHOLDT, 2009 y PEREIRA, 2001, 2005; para el argentino GANCEDO, 2015 y WELSCH, 2018a. 


\section{2:}

dimensión espacial de las prácticas budistas ${ }^{2}$ en la sede argentina de la Soka Gakkai (en adelante SGIAR) y su vinculación con sus estrategias de presentación. La particularidad de esta organización, que hace de este estudio un desafío que vale la pena afrontar, es su gran descentralización espacial, tanto en lo referente a las prácticas rituales cotidianas, como a la organización de diversas actividades, ya sea para miembros de la organización o para un público más amplio. Esto hace que en cada uno de estos contextos las formas de apropiación del espacio, de atribuirle sentidos y de usarlos sean cambiantes, y una mirada sobre esta variedad permite aproximarse a las diversas maneras en que la organización interactúa ante distintos actores, cómo se posiciona y muestra ante ellos. Mi objetivo en este trabajo será entonces indagar sobre cómo SGIAR construye su propia imagen, como organización budista religiosa y como ONG humanista, a partir de sus formas diferenciales de producir y de otorgarle sentidos a esos espacios.

Empezaré repasando brevemente la historia de la Soka Gakkai, sus prácticas, creencias y su forma de organización. Este recorrido servirá como introducción a la cuestión espacial, para entender por qué hablamos de una supuesta doble faceta y la importancia que ambos aspectos tienen para el desarrollo de la institución, que es lo que está en juego cada vez que SGIAR o sus miembros se presentan como tales. Haré algunas aclaraciones sobre su concepción del humanismo, cuyo sentido amplio retomaré a lo largo de este trabajo. Me detendré después en algunos autores que se dedicaron al análisis antropológico del espacio, desde perspectivas tanto de corte sociológico como fenomenológico, recuperando además aportes conceptuales hechos desde la sociología y la geografía. Pasaré luego al tema principal de este trabajo, poniendo en relación las formas de sociabilidad de los miembros de SGIAR con la disposición del espacio y las prácticas institucionalizadas a partir de las cuales estos son apropiados dándoles sentidos particulares de acuerdo con determinados objetivos. Analizaré algunas consecuencias de estas estrategias y los modos de vinculación que de ellas se desprenden, en las que encontramos también formas específicas de construcción identitaria.

\footnotetext{
2 Salvo indicación contraria, en adelante los términos generales "budismo" o "budista" serán utilizados solamente en referencia al budismo practicado por los miembros de la Soka Gakkai. 


\section{De budismo y humanismo: historia y organización de la Soka Gakkai}

El carácter de la Soka Gakkai ha ido cambiando a lo largo de su historia, y es la imbricación entre estos cambios y las prácticas y filosofía sobre la que se basa, los que fueron dándole forma a ese carácter ambiguo que se mueve entre lo religioso y lo humanista. Antes de ver qué implica esta idea de humanismo, presentaré su historia a través de una breve cronología.

La Soka Gakkai fue creada en Japón, en 1930, como un grupo de estudio. Sus fundadores eran maestros y educadores que encontraron en el budismo de Nichiren Daishonin la base para un nuevo sistema educativo cuyo objetivo sería formar a los niños para que desarrollen sus potenciales logrando una vida feliz. Pocos años después, durante la Segunda Guerra Mundial, las críticas al gobierno llevaron al arresto de los líderes de la organización. Su primer presidente, Tsunesaburo Makiguchi (1871-1944) murió en prisión, mientras que su discípulo más cercano, Josei Toda (1900-1958), fue liberado al finalizar la guerra. Toda reconstruyó la Soka Gakkai y se convirtió en su segundo presidente. Ante la devastación que había dejado la guerra, cambió el eje de acción y la convirtió en una organización principalmente religiosa. En forma paralela, empezó una campaña para la prohibición de las armas nucleares y en busca de la paz del mundo, sin abandonar los pilares de la educación y la cultura. Por esta época Toda se dirigió a los jóvenes de la Soka Gakkai y les encomendó la misión de concretar el kosenrufu, la paz del mundo a través de la felicidad de las personas. Los jóvenes de la sede argentina actualmente hablan de ese acontecimiento como una fuente de inspiración para dedicar sus vidas a ese objetivo, luchando por la felicidad de todos.

En 1960 Daisaku Ikeda asumió la tercera presidencia de la organización en Japón y se lanzó en su primer viaje por el mundo, llevando este budismo a distintos países en los que, pocos años más tarde, se irían creando sedes locales. Las primeras en Sudamérica fueron Brasil en 1960 (BORNHOLDT, 2009), Paraguay en 1963 (SGIPy s/f) y Argentina en 1964 (GANCEDO, 2015; WELSCH, 2018a), seguidas por países del resto de la región. En 1975 Ikeda creó la Soka Gakkai Internacional (SGI), organismo que nuclea a todas las sedes alrededor del mundo y que funciona oficialmente como ONG desde comienzos de la década de 1980, cuando fue registrada como tal en la Organización de las Naciones Unidas (SGI, s/f). En Argentina fue registrada en el Registro Nacional de Cultos como Asociación Religiosa Soka Gakkai Internacional de Argentina en 1980. 
La práctica budista de SGIAR consiste en el daimoku, la entonación diaria de nam myoho rengue kyo ("entrega devota al Sutra del Loto”) ${ }^{3}$. Esta fue revelada en el siglo XIII de nuestra era por el monje japonés Nichiren Daishonin, como la forma correcta para manifestar la budeidad inherente a todos los seres. Se realiza todos los días seguida por el gongyo, la recitación en japonés de fragmentos del Sutra del Loto. Quienes ingresan como miembros a SGIAR reciben un Gohonzon, reproducción del pergamino inscrito por Nichiren que corporifica la Ley Mística de nam myoho rengue kyo y frente al cual se hace el daimoku.

Tras la refundación bajo el mando de Toda como organización religiosa se mantuvo la naturaleza de los encuentros de diálogo entre sus miembros, por lo que los grupos de estudio siguieron funcionando y hasta la actualidad son una herramienta esencial para la difusión del budismo. Una vez por semana los miembros que viven en el mismo barrio se reúnen en el domicilio de alguno de ellos, designado para tales fines, para las reuniones de estudio, y una vez al mes para las de diálogo, conocidas como zadankai. Estos núcleos barriales compuestos por hombres y mujeres de distintas edades se conocen como han, y cada uno de ellos tiene un responsable o líder. Mantener esta forma de socialización entre los miembros lleva a que, a medida que se incorporan nuevas personas a los hanes, estos deban dividirse designando nuevos domicilios para que el nuevo han se reúna, aumentando así los espacios de práctica. Los hanes están agrupados por localidades, y éstas por partidos, que en la provincia de Buenos Aires están organizados en cuatro regiones (Norte, Sur, Oeste y Ciudad Autónoma de Buenos Aires).

Los miembros se agrupan también en divisiones según género y edades, y pueden optar por participar en otros grupos, como los artísticos y deportivos. Además del daimoku y las reuniones, cada grupo y división tiene sus propias actividades: ensayos, reuniones para estudiar budismo, organizar algún evento o planificar actividades de difusión. Si bien son todas voluntarias, se anima a los miembros a participar en varias de ellas, generando así lazos sociales también entre personas de distintos hanes. Todas estas actividades son percibidas como pequeñas, y simples, contribuciones al kosen-rufu. Como vimos, este es el logro de la paz del mundo a través de la felicidad de las personas. Esta felicidad es producto de la revolución humana, el proceso por el cual una persona puede, gracias a la práctica sincera y a la fe, elevar su estado de vida hacia la budeidad. Budeidad y felicidad son frecuentemente entendidas como sinónimos, y ambos términos

\footnotetext{
${ }^{3}$ Nichiren afirmaba que de todos los sutras, las enseñanzas del Buda, los contenidos del Sutra del Loto eran los más importantes. 
involucran una actitud compasiva hacia los semejantes, el deseo de ayudarlos a ser felices, para lo que se les transmite la Ley Mística. Esta forma de difundir el budismo se conoce como hacer shakubuku, y es una manera muy concreta de ayudar al kosen-rufu.

En esa actitud compasiva y en el respeto por la dignidad de la vida yace el humanismo promovido por la Soka Gakkai. Difundir el budismo es tan importante como cualquier forma de activismo social: juntar firmas para el desarme nuclear, organizarse con los compañeros de división o del han para limpiar plazas o elaborar iniciativas para generar conciencia sobre la necesidad de cuidar el medio ambiente. El humanismo incluye todas las acciones orientadas a mejorar algún aspecto de la vida social, involucrando tanto al plano cultural como diferentes formas de compromiso social. Lo mismo sucede en el caso de las acciones proselitistas de Daisaku Ikeda: sus reuniones con intelectuales y líderes políticos de todo el mundo son presentadas como formas de promover la paz y el diálogo. Considerando todo esto, usaré también esta noción de humanismo para referirme a esta faceta de la Soka Gakkai, que permite englobar dentro de una misma categoría toda una gama de actividades con distintas características, pero percibidas como similares por sus miembros, por compartir el fin de contribuir a la sociedad. A continuación, examinaré cómo esto se plasma en formas específicas de operar sobre el espacio, así como las tramas de significados y relaciones que implica.

SGIAR cuenta con varios centros culturales propios, conocidos como kaikan. El principal es el de Villa Urquiza (CABA), donde funciona la sede administrativa central, el Auditorio de la Paz, y salas para usos varios. Junto a este funciona, desde el 2016, el Centro Soka de Mujeres por la Paz (CSMP), que cuenta con varias salas para charlas y un amplio hall de entrada para exposiciones. Hay kaikanes también en las provincias de Tucumán, Neuquén, Córdoba y Santa Fe, mientras que la provincia de Buenos Aires tiene tres (en Temperley, Castelar y Mar del Plata). Ninguno de estos edificios funciona como templo, ni está destinado a la práctica ritual. La expansión territorial de SGIAR a lo largo del país se debe en mayor parte a su tradición de realizar las prácticas grupales regulares en los domicilios de los miembros. Además de facilitar su participación sostenida en las reuniones del han (es decir, del grupo barrial), esta descentralización hace que el número de espacios ocupados por SGIAR se multiplique por la cantidad de hanes, logrando así una presencia estable en zonas lejanas a sus instalaciones y en ciudades y pueblos donde no cuenta con ninguna sede (WELSCH, 2018b). De aquí se desprende una primera consecuencia: si estos espacios se destinarán a la práctica del budismo, es necesario que sean adecuados para este fin. Y si serán un punto de reunión 
para los miembros, estos deben reconocerlos como tales y, por lo tanto, aunque sea una mínima intervención sobre el espacio se hace necesaria. Por otro lado, la Soka Gakkai le da mucha importancia al proselitismo y a la organización de actividades de difusión. A pesar de contar con espacios propios para realizarlas, aquí se replica, en cierta medida, el modelo de descentralización que observamos para la práctica cotidiana. Parte de las actividades, especialmente las destinadas a sus miembros, se realizan en los centros culturales. El resto se hace en espacios externos, ocupados solo temporalmente para estos eventos. De este punto podemos desprender dos consecuencias: primero, que estos, como los domicilios de los practicantes, deben ser adecuados a los fines del evento. Pero, y a modo de segunda consecuencia, esa adecuación no es fija y varía en tanto que lo hacen las actividades y sus asistentes. Al ser externos y de uso transitorio (por ejemplo, un club de barrio) se requiere siempre de alguna forma de modificar estos espacios que cambiará según el tipo de actividad. Así, SGIAR ocupa muchos espacios distintos, y al hacerlo los dota de significados cambiantes, y el modo en que lo hace influye a su vez en los destinatarios de los mensajes enviados a través de estas formas de apropiación espacial.

\section{Algunas pistas para pensar los espacios}

El análisis que sigue parte de la premisa de que el espacio es construido socialmente y, por lo tanto, las formas de relacionarse con él están mediatizadas culturalmente. De Certeau, definió a los espacios como "lugares practicados" y “entrecruzamiento de movilidades" (2000, p. 129), se transforman en espacios sólo a través de las prácticas sociales que les dan sentido. Están determinados no por objetos, sino por operaciones de sujetos históricos. En forma similar Evans-Pritchard afirma en su etnografía clásica sobre los Nuer (1977) que son las actividades sociales las que definen a los espacios y a los tiempos. Por su parte, Durkheim veía en ellos el reflejo de las estructuras sociales. Según este autor, para poder tener una noción del espacio es necesario organizarlo y para ello es necesario establecer distinciones, que vienen dadas por la vida social. Y la distinción fundante para él es la que separa al mundo profano del mundo sagrado (DURKHEIM, 1968 [1912]). Al estar separados, se necesita alguna forma de comunicación que posibilite el paso de uno al otro, ritos, como reglas de conducta, que permitan el vínculo con las cosas sagradas. Pocos años antes, y pasando casi desapercibido, Van Gennep había escrito sobre los ritos de pasaje, los pórticos o umbrales que permiten la comunicación entre ambos mundos (1986 [1909]). 
Desde una perspectiva fenomenológica, para Mircea Eliade (1992) es la irrupción de lo sagrado lo que crea las rupturas que permiten diferenciar el espacio, estableciendo puntos fijos de referencia (el centro del mundo) y distinguiendo espacios significativos. Las hierofanías son fundantes del mundo y no solamente dicen dónde o cómo consagrar el espacio, sino cómo comunicarse con el dominio de lo sagrado o lo trascendental. Sin embargo, lo sagrado adquiere diferentes matices en cada caso, y no siempre aparece en el mundo "profano" como algo extraordinario o que se da de una vez y para siempre; su carácter puede ser más cotidiano y no necesariamente fundante. Varios autores se han referido en forma crítica a la separación de lo sagrado y lo profano, en tanto que estos constituirían partes diferenciadas de una misma continuidad, no necesariamente opuestas entre sí. Para Rosendahl lo sagrado, como mediación entre el hombre y la divinidad, ejerce su función a través de símbolos, mitos y ritos (1996). En la misma línea, Smith (1987) se refiere a la intervención del ritual en el espacio para hacerlo sagrado, mientras que Kong propone el término "sacralidad extrínseca” para referirse a las prácticas que intervienen en el espacio haciéndolo sagrado (1992). Asimismo, Eloísa Martín ha propuesto hablar de "prácticas de sacralización" para dar cuenta de "los diversos modos de hacer sagrado, de inscribir personas, lugares, momentos, en esa textura diferencial del mundo-habitado" (2007, p. 77). Desde esta perspectiva, las cosas se hacen sagradas a través de determinadas prácticas, y esa sacralidad puede ser temporal y formar parte de la mundanidad. Esto permite un abordaje más fino para casos como el de SGIAR, donde no hay una distinción clara entre sagrado y profano, pero donde sí se observan prácticas relativas a la sacralidad.

Aceptando la importancia de lo social en la constitución de los espacios, abordaré también el papel de las interacciones sociales, ya que la vida social es heterogénea y por lo tanto llena de fines e intereses que, así como a veces se superponen también se contradicen o, simplemente, son distintos. Erving Goffman (2017 [1959]) ha analizado el modo en que una persona interactúa con otros, dando información sobre sí misma, intentando definir la situación y manipular la impresión que generará en sus interlocutores en función de fines específicos. En estas acciones, más o menos conscientes, influyen los objetos y espacios en donde se da el encuentro, generando una impresión particular al recurrir tanto a lo verbal y corporal, como a lo no verbal. Para dar cuenta de estas formas materiales de contribuir a la presentación recurre a los conceptos de fachada, medio (setting), región anterior (front region) y región posterior (back region) que retomaremos más adelante. 
Pensando en que la heterogeneidad social implica diferentes formas de imaginar el espacio, la geógrafa Doreen Massey ha conceptualizado al espacio en base a tres proposiciones básicas: como producto de interrelaciones sociales, como esfera en la que coexisten múltiples trayectorias y, consecuencia de estas dos, como un devenir continuo, siempre en proceso. El espacio es tan dinámico como las interacciones simultáneas que se dan en la multiplicidad de trayectorias que se encuentran en él y que le dan forma, a la vez que son moldeadas por él. En este sentido, es abierto y da lugar a la impredecibilidad, en tanto que todo está siempre ocurriendo, no hay cierre y, por lo tanto, el futuro está abierto a lo nuevo. De esta forma, entendiendo la mediación sociocultural que aparece entre el espacio y los sujetos, es posible comprender también que no hay nada de natural en la forma en que aquellos están organizados, sino que, al contrario, lo que hay es reflexividad e intencionalidad asociada a la subjetividad de los distintos actores intervinientes. Por último, quiero recuperar algunos conceptos de Paola Jirón, como "lugarización móviles”, "lugares móviles” y “transientes” (2011), que permitirán reflexionar sobre las formas, temporales y simultáneas, en que distintos sujetos se apropian de un mismo espacio, sea este móvil o fijo.

La diversidad de espacios que habita SGIAR y los objetivos con que lo hace lleva a diferentes formas de producción espacial, en las que se ponen en juego distintas estrategias que envuelven a su vez distintas redes de significación. Las formas en que los diferentes actores pueden participar de esa producción son desiguales y dependen no solamente del contexto, sino de las posiciones que ocupan en la estructura jerárquica de SGIAR. Mientras que en algunos casos su capacidad de movimiento y acción es más restringida, en otros adquiere mayor libertad y esto repercute también en los vínculos que se entablan o refuerzan entre estos grupos de personas. Así, las relaciones jerarquizadas se materializan en las capacidades que tienen los sujetos, desde sus posiciones, de actuar sobre el espacio, tanto en su definición como en el modo de habitarlo.

\section{Rituales y sacralizaciones}

En primer lugar, me voy a ocupar de los espacios utilizados durante la práctica ritual. Como ya vimos, el ritual budista consiste -a nivel individual- en las recitaciones del daimoku y gongyo, y a nivel colectivo en la participación en las reuniones de los hanes. Dijimos también que quienes ingresan como miembros de la organización reciben un 
Gohonzon, el objeto sagrado frente al cual deben hacer el ritual. "Recibir Gohonzon" refleja la decisión de abrazar el budismo. Implica también un cambio de categoría: marca el pasaje de shakubuku+ a miembro. Y lo que podríamos llamar el rito de pasaje consiste, por un lado, en una breve ceremonia en kaikan, donde se le entregan sus Gohonzon a todos los que ingresan y el certificado reconociéndolos oficialmente como miembros de SGIAR. Por el otro, consiste también en la necesidad de encontrarle una ubicación en la vivienda. En esto pueden colaborar los compañeros del han o de la división, yendo a la casa del nuevo miembro y viendo qué sitio parece más apropiado para ubicar el butsudan, la "casa del buda" donde se coloca el Gohonzon para protegerlo. Normalmente se elige la sala de estar o el comedor, de acuerdo con la disposición de los muebles. Podemos identificar ciertas prácticas de sacralización, en tanto que, como objeto sagrado, hay ciertas pautas que se deben seguir para el cuidado, uso y disposición del Gohonzon. En primer lugar, se lo acompaña con pequeños ornamentos, como flores y velas, y objetos utilizados durante el daimoku: el gong, que se hace sonar durante el gongyo, una bandeja para las ofrendas de alimentos, inciensos y el $j u z u$ (elemento que se sostiene entre los dedos durante la invocación). En muchos casos, se agregan también fotos del maestro Daisaku Ikeda recortadas de las publicaciones mensuales de SGIAR. Se pueden encontrar también fotos de familiares, cartelitos con alguna frase de aliento de Ikeda o de Nichiren. La forma en que se disponen todas estas cosas y el significado que le otorgan es subjetiva. Podemos aventurar la hipótesis de que algunas personas sientan que la cercanía con el Gohonzon impregna a estos objetos con cierta sacralidad. Lo más importante, y que debe cumplirse en todos los casos, es que el Gohonzon quede cubierto por unas pequeñas puertas para protegerlo.

El espacio así dispuesto mantiene sus características, la presencia del butsudan en sí puede funcionar como indicio de que algo fuera de lo regular sucede allí, pero no lo transforma en sagrado. Durante el día, puede usarse para todo tipo de cosas: almorzar, estudiar, trabajar, reunirse con amigos. Esto cambia durante el ritual, cuando se abren las puertas que protegen al Gohonzon. La invocación del daimoku comprende muchos significados en la filosofía budista. No es solamente decir el nombre del Sutra del Loto, sino que, decía Nichiren, equivale a leerlo, por lo que cada invocación tiene el mismo poder que cada lectura. Además de expresar la Ley Mística de causa y efectos

\footnotetext{
${ }^{4}$ Este término tiene varios sentidos. Remite a un método de difusión del budismo y designa también a los destinatarios de ese método que empezaron a practicarlo y participan, aunque informalmente y de manera más o menos regular, en algún han. 
simultáneos, es esa Ley. Y al invocarla se manifiesta la budeidad interna y se conecta con ella, lo que equivale a decir que, al invocar nam myoho rengue kyo, la persona se conecta con lo trascendental (para un desarrollo más detallado ver WELSCH, 2016). Y el Gohonzon, como corporificación de nam myoho rengue kyo es también esa trascendentalidad. De esta forma, la práctica de abrir las puertas es, siguiendo a Eliade, abrir el espacio del mundo ordinario a esa realidad última que está más allá y conectarse con ella. Con esto quiero decir que el espacio no es sagrado, ni lo hace sagrado la presencia del butsudan, sino que lo hacen sagrado las prácticas en torno a estos objetos. No hay una distinción excluyente entre el mundo profano y el sagrado, pero sí una apertura simbólica del espacio ordinario a lo trascendental que se corresponde temporalmente con el momento del daimoku, cuando la budeidad, la interioridad del sujeto, se conecta con la exterioridad, en palabras de Ikeda, cuando "el microcosmos de la persona abraza el universo" (2004, p. 42) y se encuentra, en ese otro espacio trascendental, con todos los budas, del pasado, presente y futuro (el Buda, Nichiren y todos aquellos que invocan la Ley). Al finalizar, las puertas vuelven a cerrarse y la conexión exterior con el macrocosmos se cierra, pero se considera que por dentro algo sigue en movimiento. Volviendo a la descentralización espacial de la práctica en SGIAR, podemos ver que, a través de esta forma de organización, se abren pórticos hacia esa realidad esencial que están dispersos por el territorio y se multiplican cada vez que se emplaza otro Gohonzon.

En este caso se conjugan reglas institucionalizadas y estables relativas al Gohonzon con gustos personales en lo que respecta a su ornamentación y experiencias subjetivas en relación con las sensaciones evocadas durante el daimoku.

\section{(Des)marcando espacios: ONG, legitimidad y vinculación local}

Distinto es el caso cuando pensamos en los espacios donde se realizan los distintos eventos de SGIAR. Estos pueden diferenciarse tanto por sus temáticas como por sus destinatarios. En el primer caso, podemos identificar los "de budismo" y los "de humanismo" o "de ONG”. Esta distinción remite a las formas en que SGIAR se presenta, enfatizando en los primeros las cuestiones relativas al budismo, su historia y filosofía, y en los segundos las referentes a la cultura, los derechos humanos, la paz. En el otro caso, podemos diferenciar la composición del público: sólo miembros, la inclusión de los shakubukus, o un público general, que incluye además invitados más o menos reconocidos 
en representación de instituciones académicas, culturales y estatales. Si bien todos estos públicos pueden estar presentes en ambos tipos de eventos, de budismo y de ONG, lo más común es que los primeros sean para miembros y shakubukus, y los segundos para un público general. La mayor diferencia en los de ONG es la clara intencionalidad de aprovecharlos para mostrarse como algo más que una religión, como una organización que se ocupa no solo del bienestar espiritual de sus fieles, sino del bienestar general de toda la sociedad. En este sentido se recurre a distintas estrategias para señalar las ventajas que su presencia proporciona a la comunidad, en especial a través de las acciones solidarias de sus miembros, y cómo su filosofía está alineada con los valores sociales generales, como la solidaridad, el cuidado del medio ambiente o la promoción de las artes. Esto se logra principalmente a través de un despliegue visual que hace de apoyo a lo verbal.

Teniendo en cuenta que los eventos de budismo no suelen convocar tanto público, se realizan mayormente en las instalaciones de SGIAR y sus asistentes son casi en su totalidad miembros e invitados de estos, que incluyen shakubukus, pero también (en menor medida) personas que no saben nada sobre budismo y quieren conocer. Ocasionalmente se gestionan algunos espacios chicos en clubes, escuelas o centros culturales barriales, a través de miembros vinculados con ellos. Estas iniciativas surgen muchas veces en los hanes y no requieren demasiada movilización de recursos. La intervención sobre los espacios es bastante reducida, y no va más allá de algunas pancartas o adornos. Cuando se realizan en kaikan sucede algo similar, aunque a veces los talleres o seminarios sobre budismo son acompañados de alguna actividad cultural, como festivales de música o exhibiciones artísticas, y reciben más atención: se promocionan más, se anima a todos a invitar gente, y es más probable que haya alguna exhibición en el hall de entrada. En estos eventos hay una mezcla religiosa y humanista, en la que se habla sobre la práctica budista y sus beneficios, pero al finalizar estas charlas el evento pasa a ser algo puramente cultural. Vemos en estos casos un ambiente más ambiguo, donde se pueden reconocer elementos tanto de la faceta religiosa como de la humanista, y esta ambigüedad aparece también en la forma en que se presenta el evento y la organización. En estos casos se trata de promover el budismo, exhibiendo un ambiente atractivo, relajado y propicio para desarrollar la creatividad.

Los espacios propios de SGIAR, a excepción de las salas que cuentan con un butsudan, no llevan demasiadas marcas religiosas. Son edificios modernos, de colores claros, mucha luminosidad y con pocos objetos: unas pocas sillas y algunos cuadros con 
imágenes de flores en las paredes. La decoración de las salas es similar, a excepción de las salas grandes, que se distinguen por el butsudan de grandes dimensiones rodeado de flores y ofrendas de frutas. En salas más chicas, si hay uno, es de menor tamaño y no cuenta con tanta decoración. Son lugares limpios, espaciosos, que (vacíos o con pocas personas circulando) generan una sensación (especialmente las salas grandes) de paz y cierta solemnidad. Durante los eventos esta percepción cambia con el movimiento de la gente. Las escasas marcas netamente religiosas se limitan a los butsudanes y sus ornamentos. Esto hace que su sacralización, más allá de abrir las puertas quedando expuesto el Gohonzon como en los domicilios, no sea necesaria. Lo mismo podemos decir para el otro tipo de eventos, donde lo religioso pierde protagonismo. Al ser pocas las marcas religiosas, un movimiento inverso de desacralización tampoco es necesario. Por este motivo, me referiré a las marcas, temporales, que se inscriben en el espacio a través de procesos de acomodación. Retomo esta idea de acomodación de David Snow y su análisis sobre las formas estratégicas de adaptación y acomodación de la SGI de Estados Unidos (SGI-USA) al entorno sociocultural de ese país (1979). En ese trabajo pude encontrar antecedentes muy similares a lo que vengo observando en Argentina, aunque dentro de una coyuntura sociohistórica muy distinta ${ }^{5}$.

En los eventos grandes de ONG no queda lugar para la ambigüedad entre lo religioso y humanista observada anteriormente. Me parece adecuado el concepto de acomodación, en tanto que no se trata de quitar u ocultar cosas, sino de agregar y acomodar, asegurándose de que estén alineadas con lo que va a suceder en el escenario. Así, los sentidos con que se impregna el espacio refuerzan las palabras e imágenes que se transmiten en el evento. Me voy a referir especialmente a las Cumbres de Jóvenes, eventos de gran escala que se realizan todos los años en conmemoración de la visita de Daisaku Ikeda a la Argentina en 1993, y a los que se invita a personalidades de la cultura y política local. Estas cumbres se realizan en distintos lugares y formatos: por ejemplo, en el año 2019 se llevó a cabo en el microestadio de Tecnópolis, en el partido bonaerense de Vicente López, y, como en otros años, fue organizada conjuntamente por todas las regiones de la provincia de Buenos Aires y CABA. En el 2020 se optó por hacer varias

\footnotetext{
${ }^{5}$ La investigación de Snow tuvo lugar en las décadas de 1960 y 1970, en el contexto de las contraculturas hippies, el auge de la psicologización y la expansión de las prácticas y terapias alternativas vinculadas con la llamada Nueva Era, cuando los movimientos religiosos orientales eran todavía poco conocidos. En este sentido, Snow habla de una intención por parte de SGI-USA de evitar sospechas y estigmas hacia sus prácticas y conceptos budistas, poco conocidas en la sociedad norteamericana.
} 
cumbres regionales $^{6}$ (modalidad también utilizada anteriormente), siendo la principal la que se hizo en el Polideportivo Carlos Cerruti de la Ciudad de Córdoba. Las cuatro regiones del Área Metropolitana de Buenos Aires (AMBA) tuvieron cada una su propio evento, quedando el kaikan de Villa Urquiza reservado para la región Norte ${ }^{7}$. La novedad estuvo en que cada región, durante las semanas previas, organizó diversas actividades en espacios públicos (parques, plazas, clubes) convocando a vecinos de sus localidades. Hubo acciones comunitarias de distintos tipos, la mayoría al aire libre: talleres artísticos, charlas sobre reciclaje, plantación de árboles, clases de baile, música en vivo. El gran cierre de esta seguidilla de actividades fueron las cumbres. Las estrategias desplegadas en estas fueron similares: un cordón de jóvenes recibiendo al público y acompañando el ingreso al predio hasta el sitio del evento; exposiciones con actrices interpretando a varias de las figuras homenajeadas; presentaciones de los grupos artísticos (coro y baile) e invitación a personas reconocidas de distintos ámbitos.

Así, los procesos de acomodación del espacio apuntan a crear una red semántica que incluya todos aquellos aspectos que desde SGIAR se incluyen en la noción de humanismo. Lo más visible es lo cultural y lo social. Algunas temáticas de las exhibiciones instaladas en los eventos fueron: la promoción de los Objetivos de Desarrollo Sostenible (ODS) de la Agenda 2030 de la $\mathrm{ONU}^{8}$, el reconocimiento a mujeres destacadas en las muestras "Protagonistas de una Cultura de Paz", el cuidado del medio ambiente y los peligros de las armas nucleares. Los temas de las muestras se entrecruzan, por lo que todos aparecen representados en cada exposición. La mencionada muestra sobre mujeres protagonistas es un claro gesto de alineación con el auge del movimiento de mujeres en Argentina, y abarca además diversas reivindicaciones sociales reconociendo a mujeres del campo de los derechos humanos, indígenas, laborales y del feminismo y las disidencias sexuales ${ }^{9}$. Otros temas vinculados a estos campos son el manejo de residuos, la alimentación, la protección de recursos naturales. Acompañan estas muestras informaciones generales sobre los objetivos de las cumbres, donde se

\footnotetext{
${ }^{6}$ Hubo cumbres también en otras ciudades del interior del país, como Rosario, Mar del Plata, Corrientes y Comodoro Rivadavia.

${ }^{7}$ La información sobre las cumbres fue obtenida mediante la observación participante en estos eventos, además de breves notas periodísticas de medios locales, publicaciones en redes sociales y conversaciones informales con miembros que participaron en ellas.

${ }^{8}$ En relación con el Manifiesto publicado en 2018 por Daisaku Ikeda y Adolfo Pérez Esquivel titulado "A los jóvenes del mundo, un llamado a la resiliencia y a la esperanza".

${ }^{9}$ Estas son Abuelas de Plaza de Mayo, Rigoberta Menchú, Eva Perón y Lohana Berkins. También hubo figuras de la cultura vinculadas con estos movimientos, como Aimé Painé, María Elena Walsh y Victoria Ocampo. 
cuenta que son "iniciativas de los jóvenes" de SGIAR para "promover la paz del mundo", indicando así el compromiso activo que se fomenta en los miembros y cómo se lograría esto:

Creemos que el encuentro con los demás y el diálogo (...) son capaces de imprimir una nueva dirección a las fuerzas que dividen a los seres humanos (...) [para] cambiar el rumbo de la época (...) El proceso mediante el cual cada uno de nosotros, en su propio ámbito de actividades, busca crecer y mejorar haciendo relucir su máximo potencial inherente, en beneficio de las demás personas, de la sociedad y del futuro (...) se llama "revolución humana".

Siguiendo a Goffman (2017 [1959]), vemos aquí cómo se intenta definir la situación construyendo la fachada de ONG a través de impresiones generadas mediante el establecimiento de un medio (setting) donde se ve, escucha e interactúa con una ONG humanista. Esta impresión es generada también con gestos, palabras y formas de referirse a sus representantes y a su historia. Veamos un ejemplo:

\footnotetext{
[Soka Gakkai] es un movimiento global que busca promover la aplicación de la doctrina budista [del sacerdote $]$ Nichiren Daishonin (...) una filosofía de vida basada en crear un futuro basado en la dignidad [y] empoderando a las personas (...) Nuestro presidente Daisaku Ikeda, con reconocimientos y distinciones internacionales por su incansable lucha por la paz y que publicó libros junto a personalidades destacadas entre los que se encuentra el Premio Nobel de la Paz Adolfo Pérez Esquivel (...) [el objetivo de SGI es el] logro del kosen-rufu, y ¿qué es el kosen-rufu? Es concertar la paz en el mundo a partir del cambio del individuo. (Extraído de mis notas de campo. El énfasis es mío)
}

Ikeda aparece como presidente, y no como maestro, la Soka Gakkai es un movimiento global y su budismo es una filosofía, no religión. Se enfatiza el bienestar general como razón de ser de la organización y los avales con que cuenta: los reconocimientos y distinciones por su lucha por la paz y el diálogo con personalidades destacadas. Sin embargo, el afecto de los miembros hacia su maestro, según ellos mismos explican, se debe principalmente a los alientos, enseñanzas y a los esfuerzos de Ikeda por difundir el budismo.

Siguiendo las proposiciones de Snow et. al (1986), estas exposiciones y formas de presentación pueden interpretarse como estrategias de alineación de marcos, en las que se intenta demostrar que los intereses de la Soka Gakkai son los mismos que los del país, coherentes con una sociedad democrática y moderna. La apelación a los ODS de la ONU, al manifiesto publicado conjuntamente por Ikeda y una figura reconocida como 
Pérez Esquivel ${ }^{10}$, constituyen también formas de legitimación de su actividad humanista, al presentar sus vinculaciones oficiales con personajes e instituciones ampliamente reconocidos. Esto concuerda con las observaciones de Snow (1979) sobre la SGI-USA, por lo que podemos ver que no son estrategias nuevas, sino que persisten y a medida que las sedes locales crecen se van adaptando a los distintos países. En nuestro caso, cabe destacar además las invitaciones a funcionarios públicos, que a lo largo de los últimos años (y en este tipo particular de eventos) han incluido desde intendentes y otros funcionarios municipales, representantes de Direcciones de Cultos, hasta ministros nacionales de carteras como Educación, Cultura y Desarrollo Social. En el trabajo citado, Snow se refirió a la cuestión de la legitimidad que otorga contar con la presencia oficial de representantes públicos, pero debemos agregar que esta se relaciona también con el establecimiento de vínculos institucionales a largo plazo, lo que explica la invitación a funcionarios de los dos grandes partidos que han gobernado durante las últimas décadas ${ }^{11}$. Todo esto contribuye a definir la situación en términos de interacción con una ONG, que se construye, como advierte Goffman, de forma consciente pensando en quienes son los interlocutores y las expectativas de estos para aceptar, o rechazar, la situación definida por SGIAR.

No sería del todo errado afirmar que SGIAR efectivamente logra estos objetivos de presentarse como una ONG humanista. Durante años ha establecido vínculos con distintas instituciones y recibió reconocimientos de varias universidades argentinas, así como de diferentes agentes gubernamentales. Considerando que la participación en estos eventos no aparece en los relatos de conversión de los miembros, creo que los verdaderos destinatarios del mensaje de ONG humanista son quienes participan como invitados de SGIAR. Si el objetivo fuera atraer a nuevos miembros, podemos aceptar que haya quienes decidan conocer más luego de haber participado en ellos. Pero es poco probable que se espere esto de los académicos y funcionarios públicos invitados. Pienso que la idea es generar una imagen pública que inspire confianza, que le de legitimidad y que demuestre un anclaje social concreto; en otras palabras, que demuestre su utilidad para la sociedad argentina logrando posicionarse como un jugador potencialmente valioso en la arena sociopolítica del país. Un dato en favor de esta hipótesis son las distinciones

\footnotetext{
10 Referente del SERPAJ (Servicio Paz y Justicia), organización promotora de la cultura, derechos humanos y no violencia. Pérez Esquivel recibió el Premio Nobel de la Paz en 1980, y es uno de los llamados "amigos Soka", en virtud de los diálogos que mantiene desde hace varios años con Ikeda. ${ }^{11}$ Me refiero al peronismo representado por el Frente para la Victoria/Frente de Todos, que gobernó en entre 2003-2015 y desde 2019 al presente, y al frente Cambiemos/Unidos por el Cambio, que lo hizo entre 2015-2019. 
otorgadas por la Legislatura de la Ciudad Buenos Aires y el Senado de la Nación Argentina en el año 2016 a Daisaku Ikeda ${ }^{12}$ días después de que Hernán Lombardi, entonces Titular del Sistema Federal de Medios y Contenidos Públicos, participara en la Cumbre de Jóvenes realizada en Tecnópolis. Las distinciones fueron recibidas por Minoru Harada, presidente de la Soka Gakkai japonesa quien estuvo junto a él en la cumbre. Unos meses después varios funcionarios del Gobierno de la Ciudad de Buenos Aires, incluyendo al Jefe de Gobierno Horacio Rodríguez Larreta, presenciaron la inauguración de CSMP, donde también estuvo Harada. Dos años después, en el 2018, la Secretaría de Culto de la Nación Argentina dedicó algunas publicaciones en su página de Facebook a las relaciones institucionales con SGIAR, y en octubre de ese año el hijo de Daisaku Ikeda, Hiromasa Ikeda (presidente actual de SGI) fue recibido por el presidente Mauricio Macri. En las imágenes del encuentro, se lo ve también a Lombardi ${ }^{13}$.

Así, lo que está en juego es la construcción de una imagen de ONG que debe ser acorde a lo que los representantes del Estado, las universidades u organizaciones sociales que estén en el público, consideran como tal. Viotti y Funes (2015) han trabajado sobre las controversias desatadas por las relaciones entre el Gobierno de la Ciudad de Buenos Aires y el Arte de Vivir (movimiento que también se mueve entre la espiritualidad y la $\mathrm{ONG}$ ) en las que la presencia de lo espiritual en ámbitos públicos (espacios estatales, escolares) tuvo un papel central como el blanco de las críticas de la oposición política. Tal vez es en ese sentido que debemos interpretar el corrimiento de lo religioso a un segundo plano, como una adecuación a lo que una ONG que quiere un lugar en la arena pública debería ser. Esto explicaría la escasa presencia del budismo, mencionado marginalmente y en términos de filosofía. Digo escasa, porque no es algo que se intente ocultar o invisibilizar completamente, sino que pasa a segundo plano al mostrarse como una ONG socialmente comprometida y moderna, adecuándose a la idea contemporánea de modernidad, que viene de la mano de la secularidad: su anclaje hacia afuera, hacia la sociedad en general, es decir, su anclaje público, es humanista. Hacia

12 Ver las notas publicadas en: http://www.radiodeloeste.com.ar/noticias/el-senado-argentinootorgo-la-mencion-de-honor-senador-domingo-faustino-sarmiento-al-maestro-ikeda/ y http://www.expectativa.com.ar/lalegislaturaportenayelsenadodistinguieronadaisakuikedapreside ntedelasgi/.

13 La nota del 30 de octubre de 2018 está disponible en el sitio web oficial de la Presidencia de la Nación: https://www.casarosada.gob.ar/informacion/actividad-oficial/9-noticias/44015-macrirecibio-al-vicepresidente-de-la-organizacion-budista-soka-gakkai-internaciona. A pesar del alto rango de estos funcionarios, no hubo publicaciones al respecto en los medios de comunicación masiva más importantes. 
adentro, el privado, donde interactúa con sus miembros, es religioso. De esta forma se evitan sospechas o críticas por ocupar espacios que, como religión, no le corresponderían.

Otra estrategia de acomodación, más cercana a las que analiza Snow (1979), tiene que ver con la vinculación con la historia y cultura local. En estos grandes eventos es común que el coro cante alguna canción del acervo musical popular argentino y que la orquesta y los bailarines interpreten tangos o chacareras. Asimismo, cantantes y actores famosos a nivel nacional y que son miembros de SGIAR colaboran frecuentemente interpretando sus canciones en vivo, como los cantantes Louta y Militta Bora, o leyendo algunas palabras, como la actriz Karina K. Esta estrategia logra darle mayor visibilidad a la organización entre personas sin ningún tipo de relación con SGIAR, que siguen a estos artistas en sus redes sociales y acceden por lo tanto a las publicaciones que ellos hacen sobre los eventos más grandes. Teniendo en cuenta que en todo tipo de eventos la mayor parte del público consiste en miembros, shakubukus y sus familiares o amigos, esta contribución adquiere bastante relevancia para una difusión más masiva, obteniendo mayor visibilidad. Además de esto, y como observaron Carini y Gracia en el caso de la celebración del Vesak por parte de la comunidad taiwanesa (2016), estas estrategias son también formas de acercarse a la sociedad argentina estableciendo puentes hacia su cultura e historia, al recuperar tradiciones e imágenes evocadas como representantes de la identidad nacional - el tango y la música folclórica, las imágenes de figuras de gran peso social y político, la participación de artistas populares reconocidos. Si bien entre los miembros el número de japoneses y descendientes de migrantes de ese país es muy bajo, muchos líderes y coordinadores de las distintas divisiones son de origen japonés, al igual que los representantes de sus asociaciones internacionales. Así se logra neutralizar lo japonés, y por ende lo extranjero, en su imagen pública (aunque a nivel interno los términos japoneses y el vínculo con ese país sean muy significativos). Es una manera de moverse de su lugar periférico en el campo religioso nacional y acercarse un poco hacia el centro ${ }^{14}$, relativizando sus elementos exóticos y obteniendo una legitimación de su accionar nada menos que de parte del Estado Nacional.

\footnotetext{
${ }^{14}$ Según el modelo propuesto por Wright y Ceriani Cernadas $(2011,2018)$. 


\section{Circulación y sentidos heterogéneos}

Por último, me gustaría referirme a los asistentes de los eventos y a la cuestión de su circulación y apropiación de los espacios, que adquiere diferentes formas según estos se realicen en los centros culturales de SGIAR o en predios más grandes.

Al llegar a estos lugares, ya sea para un evento de budismo de menor escala o para las cumbres, siempre hay un grupo de jóvenes que se dedica a recibir a los asistentes, orientarlos ante cualquier duda y, más importante, indicar el camino que deben seguir para participar de la actividad. Los encargados de esto último arman dos filas enfrentadas marcando el camino saludando a las personas que van pasando entre amplias sonrisas y aplausos. De esta forma, se marca la vía a seguir, dirigiendo al público a los espacios que conforman la "región anterior" o front region de Goffman (2017 [1959], p. 125): todos aquellos lugares y elementos que sirven para generar la impresión deseada. Al mismo tiempo, quedan delineadas las "regiones posteriores" o back regions (2017 [1959], p. 130), aquellos sectores restringidos al público, donde solo se puede ver a quienes participan de la organización del evento. Esta restricción puede interpretarse de distintas formas, y tiene diferentes características. Es más notoria en los centros culturales que en lugares como Tecnópolis u otros predios de mayor tamaño y capacidad de público. Y estas restricciones influyen en el comportamiento de las personas de distintas maneras.

En el caso de kaikan, se trata en principio de restringir el acceso a los lugares donde funcionan las oficinas y espacios administrativos; como cualquier lugar de trabajo, su acceso se limita a su personal. Tampoco parece relevante permitir el acceso a salas vacías, donde hay mobiliario y otros objetos que se deben cuidar. Pero también podemos conjeturar, sobre todo en eventos de ONG, que sea una forma de evitar el acceso a los espacios no acomodados para la ocasión. Las restricciones al público se dan también controlando la circulación de las personas, especialmente en las salas grandes y el Auditorio, donde se acompaña a quienes van llegando a sus asientos, para llenar la sala ordenadamente. Se controla también que no se ingrese con alimentos o bebidas y, si está el Gohonzon a la vista, que no se tomen fotografías dentro del lugar. En lo que respecta a las interacciones entre las personas, los saludos, abrazos, las idas y vueltas a sus lugares cada vez que ven a lo lejos a algún conocido, son comunes y generan un alboroto que se termina al aparecer los presentadores, y que vuelve a comenzar cuando estos dan por finalizada la actividad. En grupitos se reúnen en las escalinatas, el patio interno y la vereda para saludarse, conversar brevemente y despedirse. Sus posibilidades de 
apropiación de estos espacios son bastante limitadas, y el poder de acción sobre ellos está de parte de quienes se ocupan de la organización del evento, quienes disponen por donde se puede transitar, en qué momento y de qué manera. Lo contrario sucede cuando se usan lugares más amplios, con espacios al aire libre, especialmente si implican distancias más largas para llegar a ellos.

En estos casos, el cordón de jóvenes recibiendo al público es más una indicación del camino hasta el ingreso que una restricción a circular por otros lados. En ellos no se observa el control sobre los espacios y los asistentes que hay en kaikan; no hay prohibiciones ni de tomar fotos ni de comer durante el evento. Solo se cuida que no queden personas de pie o bloqueando los pasillos o salidas de emergencia, y que se respeten los asientos reservados. Así se les da mayor libertad a los asistentes, quienes habitan esos lugares de distintas formas.

Estos llegan desde todo el AMBA, lo que implica en muchos casos largos viajes, y es común que compartan el auto o viajen en grupos, y en ocasiones los hanes alquilan micros para ir todos juntos. Pude compartir esta experiencia con ellos, y no pude evitar recordar las excursiones escolares, al ver el alboroto entusiasta de los grupos que viajábamos juntos y a la responsable del han en que participaba subiendo al micro los canastos con botellas de bebidas y paquetes de galletitas para compartir durante el viaje (a pesar de que en nuestro caso era bastante corto). Muchos llevan mate y alguna vianda. Así, estos lugares móviles (JIRÓN, 2011), en especial los micros, son apropiados como momentos de distensión y socialización, donde se comparte un clima de fiesta y alegría, lo que les da, especialmente a las cumbres, un matiz distinto al de otros eventos. Se experimentan como situaciones de esparcimiento y momentos para disfrutar de la familia y los amigos, en las que el festival parecería ser la excusa para hacer esta salida familiar y social. Durante las presentaciones, mientras muchos escuchan atentamente, hay también en el público quienes no prestan demasiada atención a lo que sucede en el escenario, distrayéndose con los niños, hablando y riendo con quienes se sientan al lado o compartiendo el mate y galletitas. Sin embargo, cada vez que alguien termina de hablar, inmediatamente se aplaude y arenga. A los grupos artísticos se los escucha con más atención, acompañando con el cuerpo, cantando y bailando desde el asiento, y al finalizar son aplaudidos con mucho entusiasmo.

Aplicar el concepto propuesto por Jirón de lugares transientes, espacios fijos apropiados temporalmente, permite dar cuenta de estas distintas formas de estar-ahí, donde parecería, considerando estas breves intervenciones, que lo importante es 


\section{0:}

simplemente participar y apoyar con su presencia. Algo similar se puede decir de quienes participan desde arriba del escenario, ya sea leyendo alguna reflexión, cantando o haciendo una coreografía. Acompañando los ensayos, pude percibir que lo que llevaba a muchos a participar en estos grupos era simplemente divertirse, compartir el momento con sus compañeros de han. Una mujer embarazada de siete meses que participaba en el ensayo del coro decía entre risas “ino, si no pego una nota! Vine para apoyar nada más”. Y los coordinadores animaban a sonreír, a transmitir alegría, ya que eso, decían, era más importante que cantar bien o saberse la letra de las canciones. En ambos casos, para quienes estaban arriba y abajo del escenario, se trataba de apoyarse mutuamente y aplaudir el esfuerzo hecho. Ese orden de prioridades establecido por los coordinadores también está relacionado con la impresión que intenta transmitir la organización, en este caso, de personas felices y dedicadas a promover la cultura.

¿Y quiénes son los destinatarios? Entre los miembros hay una diversidad vinculada con la estructura interna de SGIAR y la posición que se ocupe en ella: están los que deciden sobre los eventos y donde se harán, los que organizan el espacio siguiendo esas decisiones, los que participan activamente en las presentaciones (contando con poca información más allá de sus contribuciones, como pude comprobar), los que no participan en ninguno de estos grupos y asisten como público, invitando a sus conocidos, y también los shakubukus, quienes están en una posición de verdadera liminalidad turneriana (1988) con un pie adentro y otro afuera de la organización. Esto hace que también ellos sean destinatarios de lo que se muestra en los eventos, pero también (cuando se les invita a participar de los grupos artísticos) de lo que se muestra puertas adentro, en los ensayos. En estos casos las acciones tienden a generar o reforzar en los miembros (y posiblemente también en shakubukus) un sentido de identificación colectiva (FRIGERIO, 2007), en parte por las relaciones de camaradería que se promueve entre ellos, identificándose como parte de un todo que actúa con un mismo objetivo, y en parte por la demostración que SGIAR hace sobre su propia jerarquía y potencialidades al movilizar una cantidad importante de recursos materiales y humanos, y al contar con la presencia de figuras destacadas como Pérez Esquivel o funcionarios públicos de alto rango. De esta forma, se configuran en un mismo espacio diversas prácticas con sentidos, agentes y destinatarios múltiples. 


\section{Palabras finales: trayectorias superpuestas y aperturas al futuro}

Hemos visto en este trabajo que las formas de intervenir sobre el espacio de SGIAR son variadas. En los espacios ocupados regularmente durante los momentos rituales, pertenecientes a los miembros, esas intervenciones son estables y siempre mediadas por la subjetividad de estos. Me dijeron muchas veces que el budismo "es muy personal y muy vida cotidiana”, y esto se refleja en la disposición tanto del butsudan como de la sala donde está emplazado. El carácter sagrado de estos espacios viene dado por la actividad ritual que se realiza en ellos, por lo que podemos decir con Kong (1992) que se trata en este caso de una sacralidad extrínseca, producto de la intervención de las personas y la presencia de un objeto sagrado que, si bien está siempre ahí, se activa mediante la práctica de abrir las puertas que lo recubren en momentos regulares y específicos.

Por el contrario, en los espacios destinados a las demás actividades, ya sean los centros culturales de SGIAR o algún club o microestadio, las formas de apropiación son más variables y dependen de la institución, que es la que decide y determina cómo se apropian, por donde se podrá circular, en función de quiénes estarán entre el público. Sin embargo, como vimos, quienes llegan a los eventos conservan a su vez cierto margen para darles significados en formas subjetivas.

Se puede apreciar el rol significativo que adquiere la dimensión espacial como locus que genera y refuerza el desarrollo interno de SGIAR, así como su posicionamiento y vinculación con el resto de la sociedad. En el primer caso, su descentralización espacial le permite cubrir vastos territorios sin necesidad de estar presente físicamente, y se conjuga con la apertura a lo trascendental habilitada por la presencia del objeto sagrado, el Gohonzon, en los domicilios de los miembros para que dicha presencia, en términos de espacios sagrados para los rituales, no sea requerida. Por otro lado, es la forma más visible en la que despliega sus estrategias de acomodación para presentarse en formas específicas de acuerdo con los demás actores en juego. Podríamos decir que son sus formas de comunicarse con la realidad última, sagrada, a través de un objeto particular, las que posibilitan un uso de los espacios relativamente flexible que permite su fácil acomodación a diferentes fines, en especial aquellos no relacionados con lo religioso.

Hemos observado también diversas interacciones entre una multiplicidad de trayectorias que se encuentran en un mismo lugar, al que, siguiendo a Massey (1991), podemos entender como un punto de encuentro o una intersección, donde se cruza esa 


\section{2:}

gran variedad de intereses, objetivos y experiencias. El resultado de estas intersecciones debe ser comprendido en términos procesuales. Procesos sociales que pueden tener su origen en ese tiempo-espacio, que pueden venir desarrollándose desde antes o que pueden proyectarse a futuro con desenlaces inciertos.

Teniendo en cuenta la heterogeneidad de grupos que analizamos, es difícil identificar los intereses particulares de cada uno de ellos, pero creo que una conclusión que se puede extraer de este trabajo es que la superposición de actores, objetivos y formas de experimentar estos tiempos-espacios opera en diferentes niveles que se influyen entre sí, y que todo esto sucede no solo en un mismo espacio, sino en vinculación con cómo ese espacio fue construido y lo que sucede en él. Al mismo tiempo, es necesario considerar que aun cuando las relaciones parezcan plantearse entre dos partes, por ejemplo, SGIAR y el Estado, siempre hay más actores prestando atención a lo que sucede en ese nivel y extrayendo sus propias conclusiones y percepciones sobre esas situaciones, como es el caso de varios miembros y sus sensaciones ante tal despliegue. Los aportes de Massey y Goffman fueron centrales para abordar estas cuestiones y ampliar la mirada, asumiendo la complejidad derivada de la heterogeneidad interna de SGIAR y recordando que toda institución en desarrollo debe mirar tanto hacia afuera como hacia adentro. En todos los casos, aunque estas intersecciones sean limitadas espacial y temporalmente, las interacciones e impresiones que suceden en ellas quedan abiertas para continuar desarrollándose en otros tiempos-espacios creando así su propio devenir.

\section{AGRADECIMENTOS}

Agradezco a mis colegas que ayudaron a darle forma a este trabajo, especialmente al Dr. Pablo Wright y al Dr. Catón Carini por sus comentarios y sugerencias. Esta investigación se enmarca en los proyectos UBACyT 20020170100498BA y PICT 2017-3132, dirigidos por el Dr. Pablo Wright.

\section{REFERENCIAS BIBLIOGRÁFICAS}

BORNHOLDT, Suzana. "ONG ou religião? O caso da Soka Gakkai no Brasil”. En: Ciencias Sociales y Religión/Ciências Sociais e Religião, vol. 11, nro.11, 2009, pp. 181-198.

CARINI, Catón y GRACIA, Agustina. "Ritual, identidad y transnacionalización en una celebración budista: el Vesak en la Argentina”. En: Runa, vol. 37, nro. 1, 2016, pp. 5-20.

DE CERTEAU, Michel. La Invención de lo Cotidiano. 1. Artes de Hacer. Ciudad de México: Universidad Iberoamericana, 2000.

DURKHEIM, Emile. Las formas elementales de la vida religiosa. Buenos Aires: Shapire, 1968 [1912]. 
ELIADE, Mircea. Lo sagrado y lo profano. Barcelona: Labor, 1992.

EVANS-PRITCHARD, Edward E. Los Nuer. Barcelona: Anagrama, 1977.

FRIGERIO, Alejandro. "Repensando el monopolio religioso del catolicismo en Argentina". En: CAROZZI, María Julia y CERIANI CERNADAS, César. (Org.). Ciencias Sociales y Religión en América Latina: Perspectivas en debate. Buenos Aires: Biblos/ACSRM. 2007, pp. 87-1 16.

GANCEDO, Mariano. "Rostros de una diáspora. Comunidad japonesa y religiosidad en la Soka Gakkai Internacional (Argentina)”. En: Horizontes Antropológicos, vol. 21, nro. 43, 2015, pp. 183210.

GOFFMAN, Erving. La presentación de la persona en la vida cotidiana. Buenos Aires: Amorrortu, 2017 [1959].

IKEDA, Daisaku. Disertaciones sobre los capitulos "Hoben" y "Juryo" del Sutra del Loto. Buenos Aires: Soka Gakkai Internacional de Argentina, 2004.

JIRÓN, Paola. "Momentos Móviles. Los lugares móviles y la nueva construcción del espacio público". En: Arquitecturas del Sur, vol. 39, 2011, pp. 44-57.

KONG, Lily. "The sacred and the secular: Exploring contemporary meanings and values for religious buildings in Singapore". En: Southeast Asian Journal of Social Science, vol. 20, nro. 1, 1992, pp. 18-42.

MARTÍN, Eloisa. "Aportes al concepto de 'religiosidad popular': Una revisión de la bibliografía argentina de los últimos veinticinco años". En: CAROZZI, María Julia y CERIANI CERNADAS, César (Org.). Ciencias Sociales y Religión en América Latina: Perspectivas en debate. Buenos Aires: Biblos/ACSRM, 2007, pp. 61-86.

MASSEY, Doreen. A global sense of place. Marxism today, Junio 1991.

MASSEY, Doreen. For Space. Londres: Sage, 2005.

PEREIRA, Ronan Alves (2001). O budismo leigo da Sôka Gakkai no Brasil: da revolução humana à utopia mundial. San Pablo: Unicamp, 2001.

"Uma vertente budista híbrida e mutante: reflexoes sobre a Soka Gakkai Internacional e seus pesquisadores". En: III CONGRESSO INTERNACIONAL DE ESTUDOS JAPONESES NO BRASIL, 2005, Brasilia. Anais do... Brasilia: Departamento de Línguas Estrangeiras e Tradução, 2005, pp. 231-250.

ROSENDAHL, Zeny. Espaço e Religião: uma abordagem geográfica. Rio de Janeiro: UERJ, NEPEC, 1996.

SGI s/f. "International Development”. Disponible en: https://www.sgi.org/about-us/sgitimeline/history-of-the-soka-gakkai-part3.html Último acceso: abril 2020.

SGIPy s/f. "Historia de la Soka Gakkai Internacional del Paraguay". Disponible en: http://www.sgiparaguay.org/v3/sgipy/ Último acceso: abril 2020.

SMITH, Jonathan. Map is not territory: Studies in the history of religions, Leiden: Brill, 1987.

SNOW, David. "A dramaturgical analysis of movement accomodation: building idiosyncracy credit as a movement mobilization strategy". En: Symbolic Interaction, vol. 2, nro. 2, 1979, pp. 2243. 
SNOW, David; ROCHFORD JR. Burke E.; WORDEN, Steven K. y BENFORD, Robert D. "Frame alignment processes, micromobilization and movement participation". En: American Sociological Review, vol. 51, n. 4, 1986, pp. 464-481.

TURNER, Victor. El proceso ritual. Madrid: Taurus, 1988.

VAN GENNEP, Arnold. Los ritos de paso. Madrid: Taurus Ediciones, 1986 [1909].

VIOTTI, Nicolás y FUNES, María Eugenia. "La política de la Nueva Era: el Arte de Vivir en Argentina”. En: Debates do NER, año. 16, nro. 28, 2015, pp. 17-36.

WELSCH, Denise. "Conociendo la Ley: La práctica de nam myoho rengue kyo en la Soka Gakkai Argentina”. En: Ciencias Sociales y Religión/Ciências Sociais e Religião, vol. 18, n. 25, 2016, pp. 101-116.

. "Budismo por la paz y la cultura: Religión, activismo ¿e inserción política? en la Soka Gakkai de Argentina”. En: TADVALD, Marcelo.; WYNARCZYK, Hilario y MEIRELLES, Mauro (Org.), Religião, Sociedade e Política. Miradas socioantropológicas. Puerto Alegre: CirKula. 2018a, pp. 119-132.

"Passing on the Law. The Growth of Soka Gakkai International in Argentina". En: International Journal of Latin American Religions, vol. 2, $\mathrm{n}^{\circ}$. 1, 2018b, pp. 22-40.

WRIGHT, Pablo y CERIANI CERNADAS, César. "Modernidades periféricas y paradojas de la cultura: debates y agendas en la antropología de la religión”. En: CEVA, Mariela y TOURIS, Claudia (coord.). Nuevos aportes a los estudios de la religión en las sociedades contemporáneas del Cono Sur. Buenos Aires: Lumiere, 2011, pp. 145-162.

WRIGHT, Pablo y CERIANI CERNADAS, César. "Introducción”. En: WRIGHT, Pablo (ed.), Periferias sagradas en la modernidad argentina. Buenos Aires, Biblos, 2018, pp. 9-23. 